\title{
Los beneficios de la pesquisa de cáncer de pulmón mediante tomografía computada de baja dosis podrían superar los potenciales riesgos de la radiación
}

The benefits of lung cancer screening using low dose computerized tomography could be greater than the potential harms of radiation

\section{Objetivos}

Estimar la exposición acumulada a la radiación y el riesgo atribuible de por vida de la incidencia de cáncer asociados con el cribado del cáncer de pulmón utilizando la tomografía computarizada de dosis baja (TCBD) anual.

\section{Diseño}

Análisis secundario de datos de un ensayo de detección de cáncer de pulmón y análisis de riesgo-beneficio. El ensayo no aleatorizado había sido realizado en un establecimiento de Milán (Italia), a lo largo de 10 años (2004 a 2015), en el cual se aplicó la TCBD para la pesquisa de cáncer de pulmón (estudio COSMOS). El análisis secundario tuvo lugar entre 2015 y 2016.

\section{Participantes}

Fumadores asintomáticos de alto riesgo, de 50 o más años de edad, que fueran fumadores o ex-fumadores al momento del reclutamiento (al menos 20 paquetes-año) y que no tuvieran antecedentes de cáncer en los cinco años previos.

\section{Medición de resultados principales}

La exposición acumulada a la radiación a partir de TCBD y tomografía por emisión de positrones (en inglés positron emission tomography, PET) fue calculada mediante software de dosimetría; y el riesgo atribuible de por vida de incidencia de cáncer, calculado a partir del informe Efectos Biológicos de la Radiación Ionizante VII (en inglés, Biological Effects of Ionizing Radiation VII, BEIR VII).

\section{Resultados}

Rampinelli et al. BMJ 2017;356:j347.

Durante más de 10 años, 5.203 participantes (3.439 hombres, 1.764 mujeres) se sometieron a 42.228 TCBD y 635 PET. La mediana de la dosis efectiva acumulada en el décimo año de cribado fue de 9,3 mSv para los hombres y de 13,0 mSv para las mujeres. El riesgo atribuible de cáncer de pulmón a lo largo de la vida fue cuatro veces mayor para mujeres de 50 a 54 años que para los hombres de 65 años o más (5,5 vs 1,4 por cada 10.000 participantes), mientras que el riesgo atribuible del cáncer mayor a lo largo de la vida fue tres veces más grande $(8,2$ vs 2,6 por cada 10.000 participantes) después de 10 años de TC varió de 5,5 a 1,4 por cada 10.000 personas evaluadas, y de 8,1 a 2,6 por cada 10.000 personas examinadas, respectivamente. El número de casos de cáncer de pulmón y de cáncer mayor inducidos por 10 años de cribado en esta cohorte fueron de 1,5 y 2,4, respectivamente, lo que correspondió a un riesgo adicional de cáncer mayor inducido de $0,05 \%$ (2,4/5203). Se detectaron 259 casos de cáncer de pulmón en 10 años de cribado; se esperaría un cáncer mayor inducido por la radiación por cada 108 (259/2,4) cánceres de pulmón detectados a través del cribado.

\section{Conclusión}

La exposición a la radiación y el riesgo de cáncer a partir de una TCBD para el rastreo del cáncer de pulmón, si bien si no son insignificantes, pueden considerarse aceptables a la luz de la reducción sustancial de la mortalidad asociada con la detección de esta patología.

\section{Comentario}

En agosto de 2011, el Instituto Nacional del Cáncer publicó en The New England Journal of Medicine los resultados de su National Lung Screening Trial (NLST). Este ensayo clínico aleatorizado en el que se estudiaron fumadores de alto riesgo asignados a dos ramas: cribado con TCBD o con radiografía de tórax convencional. El hallazgo clave del estudio, que generó y despertó el debate, fue su conclusión: una reducción de la mortalidad por cáncer de pulmón de $20 \%$ en la población estudiada con TCBD y de un $6,7 \%$ por otras causas en comparación con el grupo cribado con radiografía ${ }^{1}$. Posteriormente, la Fuerza de Tareas Preventivas de los EE.UU. se expidió a favor de realizar el cribado de cáncer de pulmón mediante la TCBD en adultos de 55 a 80 años de edad con antecedentes de tabaquismo de al menos 30 paquetes-año y que continúen fumando o hayan dejado de fumar en los últimos 15 años, y aconseja discontinuar esta práctica una vez que hayan transcurrido 15 años sin fumar o se desarrolle un problema de salud que limite la expectativa de vida o la posibilidad de recibir tratamiento quirúrgico con fines curativos ${ }^{2}$. El objetivo del presente artículo es analizar uno de los potenciales daños de la implementación de un programa de rastreo de cáncer de pulmón con TCBD: estimar la dosis de radiación acumulada y cuantificar del riesgo de desarrollar cáncer inducido por esta. En ambos aspectos los resultados fueron aceptables, aunque no despreciables, a la luz de la considerable reducción de la mortalidad asociada al cribado. Sin embargo, los autores aclaran que no fueron considerados otros daños potenciales como la dosis de radiación emergente de una nueva cascada de estudios vinculados a la detección de hallazgos incidentales, el sobrediagnóstico (cánceres de pulmón que por su lento crecimiento no hubieran afectado la vida de los pacientes si no se trataran) y los falsos positivos. En la literatura, el porcentaje descripto de tomografías adicionales realizadas en la población que se realizó el cribado es amplio, variable entre el 1 y al 44,6\% $\%^{3,4}$. También sería interesante seguir evaluando las consecuencias psicosociales en los pacientes que se someten a la estrategia de cribado de cáncer de pulmón. Ante una TC normal el fumador: ¿deja de fumar? ¿o fuma hasta que en alguna TC aparece una imagen sospechosa?

\section{Conclusiones de la comentadora}

La decisión de iniciar el cribado debe ser compartida entre el médico y el paciente. Deberían conocerse y explicarse los beneficios y posibles daños, dejando en claro que no todos los cánceres detectados van a ser curados con seguridad ni que todos los cánceres encontrados por realizar el rastreo habrían evolucionado hasta hacerse clínicamente importantes.

Marina Ulla [ Servicio de Diagnóstico por Imágenes. Hospital Italiano de Buenos Aires. marina.ulla@ hospitalitaliano.org.ar ]

Ulla M. Los beneficios de la pesquisa de cáncer de pulmón mediante tomografía computada de baja dosis podrían superar los potenciales riesgos de la radiación. Evid Act Pract Ambul 2018;21(2):57. Comentado de: Rampinelli et al. Exposure to low dose computed tomography for lung cancer screening and risk of cancer: secondary analysis of trial data and risk-benefit analysis. BMJ 2017;356:j347

\section{Referencias}

1. The National Lung Screening Trial Research Team. Reduced Lung-Cancer Mortality withLow-Dose Computed Tomographic Screening. N Engl J Med. 2011; 365:395-409.

2. Moyer VA; U.S. Preventive Services Task Force. Screening for lung cancer: U.S. Preventive Services Task Force recommendation statement. Ann Intern Med. 2014 Mar 4; 160(5):330-8.

Intern Med. 2014 Mar 4; 160(5):330-8. Cancer. 2008 Sep; $61(3): 340-9$.

4. Sobue T, y col. Screening for lung cancer with low-dose helical computed tomography: anti-lung cancer association project. J Clin Oncol. 2002 Feb 15; 20(4):911-20. 